\title{
A multinational case-control study on childhood brain tumours, anthropogenic factors, birth characteristics and prenatal exposures: a validation of interview data
}

Danielle Vienneau, ${ }^{1,2 \#}$ Denis Infanger, ${ }^{1,2 \#}$ Maria Feychting, ${ }^{3}$ Joachim Schüz, ${ }^{4,5}$ Lisbeth Samsø Schmidt, ${ }^{4,6}$ Aslak Harbo Poulsen, ${ }^{4}$ Giorgio Tettamanti, ${ }^{3}$ Lars Klæboe, ${ }^{7,8}$ Claudia E. Kuehni, ${ }^{9}$ Tore Tynes, ${ }^{7,10}$ Nicolas Von der Weid ${ }^{11}$, Birgitta Lannering ${ }^{12}$ and Martin Röösli ${ }^{1,2} *$

${ }^{1}$ Department of Epidemiology and Public Health, Swiss Tropical and Public Health Institute, Basel, Switzerland, ${ }^{2}$ University of Basel, Switzerland, ${ }^{3}$ Institute of Environmental Medicine, Unit of Epidemiology, Karolinska Institutet, Stockholm, Sweden, ${ }^{4}$ Institute of Cancer Epidemiology, Danish Cancer Society, Copenhagen, Denmark, ${ }^{5}$ International Agency for Research on Cancer (IARC), Section of Environment and Radiation, Lyon, France, ${ }^{6}$ University Hospital Rigshospitalet Copenhagen Denmark , ${ }^{7}$ The Cancer Registry of Norway, Oslo, Norway, ${ }^{8}$ Norwegian Radiation Protection Authority, Østerås, Norway, ${ }^{9}$ Institute of Social and Preventive Medicine, University of Berne, Switzerland, ${ }^{10}$ National Institute of Occupational Health, Oslo, Norway, ${ }^{11}$ Pediatric Hematology-Oncology, University of Basel Children's Hospital, Basel, Switzerland, ${ }^{12}$ Department of Pediatrics, University of Gothenburg, The Queen Silvia Children's Hospital, Göteborg, Sweden, ${ }^{\#}$ Joint first authorship

\section{*Correspondence to:}

Prof. Martin Röösli

Department of Epidemiology and Public Health, Swiss Tropical and Public Health Institute, Socinstrasse 57, 4002 Basel, Switzerland.

Tel.: +41 (0)612848609

Fax: +41 (0)612848101

E-mail: martin.roosli@unibas.ch 
Correspondence during peer review process will be handled by:

Dr. Danielle Vienneau

Department of Epidemiology and Public Health, Swiss Tropical and Public Health Institute, Socinstrasse 57, 4002 Basel, Switzerland.

Tel.: +41(0)612848398

Fax: $+41(0) 612848105$

E-mail:danielle.vienneau@unibas.ch

Word count (exc. references): 2759

Table count: 4

Reference count: 43 


\begin{abstract}
Little is known about the aetiology of childhood brain tumours. We investigated anthropometric factors (birth weight, length, maternal age), birth characteristics (e.g. vacuum extraction, preterm delivery, birth order) and exposures during pregnancy (e.g. maternal: smoking, working, dietary supplement intake) in relation to risk of brain tumour diagnosis among 7-19 year olds. The multinational case-control study in Denmark, Sweden, Norway and Switzerland (CEFALO) included interviews with 352 (participation rate=83.2\%) eligible cases and $646(71.1 \%)$ population-based controls. Interview data were complemented with data from birth registries and validated by assessing agreement (Cohen's Kappa). We used conditional logistic regression models matched on age, sex and geographical region (adjusted for maternal age and parental education) to explore associations between birth factors and childhood brain tumour risk. Agreement between interview and birth registry data ranged from moderate (Kappa=0.54; worked during pregnancy) to almost perfect (Kappa=0.98; birth weight). Neither anthropogenic factors nor birth characteristics were associated with childhood brain tumour risk. Maternal vitamin intake during pregnancy was indicative of a protective effect (OR $0.75,95 \%$-CI: 0.56-1.01). No association was seen for maternal smoking during pregnancy or working during pregnancy. We found little evidence that the considered birth factors were related to brain tumour risk among children and adolescents.
\end{abstract}

\title{
Key words: Brain tumours; children; adolescents; pregnancy; validation
}




\section{INTRODUCTION}

Primary central nervous system (CNS) neoplasms, of which $>90 \%$ are located in the brain, are the second most common malignancy and the most common solid cancer in children in developed countries. ${ }^{1}$ While brain tumours during childhood often occur before the age of five, suggesting that both prenatal and early postnatal exposures must be considered, it remains one of the most common childhood cancers across the whole child-adolescent age spectrum. ${ }^{2}$ The annual incidence rate of CNS tumours in children aged $0-14$ years is 30 per million in Europe, ${ }^{3}$ 35 per million in Switzerland ${ }^{4}$ and 42 per million in the Nordic countries. ${ }^{5}$

Despite decades of epidemiological research, the aetiology of primary brain tumours in children and adolescents largely remains unknown. ${ }^{6}$ Apart from ionizing radiation and a few genetic syndromes such as neurofibromatosis and tuberous sclerosis, no risk factors have been identified. ${ }^{7}$ Many potential risk factors, however, have been studied including head injuries, ${ }^{8}$ maternal and paternal smoking, ${ }^{9,10}$ maternal diet (especially cured meat), ${ }^{11}$ maternal age and birth characteristics such as birth weight or birth order, ${ }^{12,13}$ atopy, ${ }^{14}$ exposure to infectious agents,,${ }^{15,} 16$ exposure to pesticides, ${ }^{17}$ parental occupation, ${ }^{18}$ maternal medication and vitamin intake during pregnancy $^{19,20}$ and electromagnetic fields from mobile phones. ${ }^{21}$ Most of these studies yielded inconclusive and conflicting results and often faced methodological limitations. The established risk factors collectively account for only $5 \%$ of all brain tumours in children ${ }^{7}$ and a recent study estimated that the majority of cancer risk is due to random mutations due to cell division - only one third of the variance in cancer risk for tissues was attributable to environmental or inheritance factors. $^{22}$

We investigated several anthropometric factors, birth characteristics and exposures during pregnancy in relation to brain tumour diagnosis among children and adolescents aged 7-19 using 
data from CEFALO, a multinational case-control study conducted in Denmark, Sweden, Norway and Switzerland. We validated the interview data with data from the birth registries to evaluate recall bias and exposure misclassification.

\section{MATERIALS AND METHODS}

\section{Study population}

\section{Cases}

Eligible cases were all children in Denmark, Sweden, Norway and Switzerland diagnosed between 2004 and 2008 with primary intracranial central nervous system tumours (CNS) aged 7 to 19 years at diagnosis. ${ }^{21}$ Brain tumours were defined as per the International Classification of Diseases tenth revision (ICD-10) and International Classification of Diseases for Oncology third edition (ICD-O-3). All diagnoses were either histologically confirmed or based on unequivocal diagnostic imaging. We examined medical records for case patients to confirm diagnosis and establish the date of diagnosis (used as reference date in the exposure assessment). Date of diagnosis was defined as the date when the first diagnostic imaging was performed. Case patients were excluded if they were diagnosed with neurofibromatosis (Mb Recklinghausen; 12 patients) or tuberous sclerosis (1 patient). Since the initial hypothesis of CEFALO was on the use of mobile phones, participants who were completely deaf prior to the reference date and children with severe mental retardation were excluded ( 2 patients and 2 control subjects). Families with insufficient language skills to complete an interview in the respective country, as judged by a nurse, treating physician, or project administrator, were excluded (15 patients and 36 control subjects). 


\section{Controls}

We randomly selected two control subjects per case patient using population registries in the participating countries, individually matched by age (Denmark, Sweden, and Switzerland: by year and month of birth; Norway: by year of birth), sex, country, and geographical region within country. In Switzerland, a two-stage random sampling procedure was applied in the absence of a national population registry. A community was randomly determined within the same language region as each patient, next the control subject was randomly selected from the corresponding communal population registry. The reference date for control subjects was same as the date of diagnosis of the matched case patient.

\section{Data collection}

Children were accompanied by at least one parent (preferably the mother) and were interviewed face-to-face by trained interviewers using a computer-assisted personal interview (CAPI) questionnaire (Denmark and Norway) or a paper version of the questionnaire (Switzerland and Sweden). In exceptional circumstances, telephone interviews were conducted with difficult-toreach participants (4 control subjects) or an adapted paper version of the questionnaire was sent (19 control subjects). Interviews with case patients and matched control subjects were mainly performed by the same interviewer. Interviewers from all centres received training at a joint workshop to ensure uniform data collection. Questionnaire translations were checked through back-translation to the master version (English), and the questionnaires were pilot-tested in all participating countries.

All case patients were interviewed within 5 years of diagnosis (63\% within 2 years). The accompanying parent responded to questions related to pregnancy and early life exposures. 


\section{Exposure information}

Interview questions were aimed at collecting both infant as well as parental characteristics. Anthropometric factors were birth weight, birth length, and age of the mother $(<25,25-34, \geq 35$ years). Birth characteristics were Caesarean section (yes, no), vacuum extraction (yes, no), use of obstetrical forceps (yes, no), if the child was born premature (i.e. $\geq 3$ weeks early; yes, no), birth order of the child in the family (1st born, later born), and if the mother ever had a miscarriage or a stillbirth (yes, no). We considered the following variables as exposures: maternal smoking during pregnancy (yes, no), maternal vitamin intake during pregnancy (yes, no), maternal intake of vitamins with folic acid (yes, no), working during pregnancy (yes, no), hours worked during pregnancy (full-time, part-time, not worked), shift work during pregnancy (yes, no), and maternal diabetes during pregnancy (yes, no).

In addition to the CEFALO questionnaire, supplementary data from national birth registries in Sweden, Denmark and Norway were obtained. Registry data were not available for Switzerland. For anthropometric factors we obtained birth weight, birth length, head circumference and gestational age in weeks. Birth characteristics comprised Caesarean section (yes, no), vacuum extraction (yes, no), use of obstetrical forceps (yes, no), ever stillbirth or miscarriage (yes, no), single or multiple births (singleton, multiple birth) and parity (first born, not first born). Specific exposures during pregnancy related to maternal smoking at first visit to maternity clinic (yes, no), working during pregnancy (yes, no) and hours worked during pregnancy (full-time, part-time, not worked).

\section{Statistical analysis}

Agreement between interview data and data from the birth registries was calculated by Cohen's Kappa. ${ }^{23}$ Weighted Kappa was used for variables with more than two categories. We considered 
agreement to be moderate if the Kappa value was 0.4-0.6, substantial for 0.6-0.8, and almost perfect $>0.8$.

Odds ratios (ORs) and 95\%-confidence intervals (95\%-CIs) to estimate the strength and precision of association between the possible risk factors and brain tumour risk were based on conditional logistic regression models matched on age, sex, and geographical region. We additionally adjusted for maternal age and parental education. To gap fill missing confounder information: we applied the most common category for parental education $(n=3)$; and for maternal age $(n=11)$ we imputed missing values based on age of the child, paternal age, country and region. All statistical tests were two-sided. For categorical variables, test for trends were calculated by assigning ordered exposure levels (e.g., 1, 2, 3). We assessed the risk for all histologic types of brain tumours combined, and specifically for astrocytoma, where numbers were large enough to allow a subgroup analysis.

The software Stata/SE version 13.0 (StataCorp, Texas, USA) was used for all analyses.

\section{RESULTS}

In total, 423 patients and 909 potential controls were identified during the CEFALO study period. Interviews were completed with 352 (83.2\%) eligible cases and 646 (71.1\%) eligible controls (Table 1). Among the 352 case patients of CNS cancer, astrocytoma was the most common type with $162(46.0 \%)$ cases (Table 1). There were $21(6.0 \%)$ cases diagnosed with ependymoma, 30 $(8.5 \%)$ with another glioma, $62(17.6 \%)$ with primitive neuroectodermal tumours, $53(15.1 \%)$ with other specified intracranial neoplasms and $24(6.8 \%)$ with unspecified intracranial neoplasms. 
The agreement between data reported in the interview and data collected from the birth registries ranged from moderate (Kappa $=0.54$ for worked and hours worked during pregnancy) to almost perfect (Caesarean section, birth weight and whether or not the child was a singleton; Table 2). Although some Kappa coefficients were marginally higher in cases, there was no evidence of a systematic difference between cases and controls.

Results for the association between reported anthropometric factors, birth characteristics and exposures during pregnancy and the risk of all brain tumours among children and adolescents are shown in Table 3; Table S1 (online supplement) shows results for the analysis restricted to astrocytoma cases. We found no evidence for an increased risk of brain tumours for any of the anthropometric factors. Children with a brain tumour were not more likely to have had a birth weight $\geq 4000 \mathrm{~g}$ compared to controls. Birth characteristics, such as intervention during birth or prematurity, did not alter the risk of being diagnosed with a brain tumour. Odds ratios seemed to fluctuate around unity and no clear tendency was seen for any of the considered birth characteristics.

Maternal vitamin intake during pregnancy was indicative, though not statistically significant, of a protective effect for childhood brain tumours (adjusted OR 0.75, 95\%-CI: 0.56-1.01; Table 3). No association, however, was observed in the subset of mothers who indicated that their vitamin supplements contained folic acid (Table 1), or in patients with astrocytoma (Table S1). All other considered exposures, such as work during pregnancy and maternal diabetes (i.e. existing maternal diabetes or maternal gestational diabetes), indicated no increased risk. Analyses restricted to astrocytoma (Table S1) gave broadly similar results compared to the full sample.

Table 4 reports the associations based on data collected in the birth registries, and compares the estimates with interview based exposure data for the same study sample (without Switzerland). 
We found no evidence for an increased risk of brain tumours for any of the measures evaluated in the birth registries. Risk estimates were similar for birth registry and interview data for all variables except smoking where risk estimates slightly above unity were observed for interview data vs. close to unity for the registry data. The 95\%-confidence intervals, however, were overlapping to a large extent. Regarding risk of astrocytoma, we saw evidence of a protective effect of working during pregnancy (adjusted OR 0.14, 95\%-CI: 0.02-0.97) and specifically for part-time work during pregnancy (adjusted OR 0.09, 95\%-CI: 0.01-0.97), though only in a small sample with interview data (Table S2).

\section{DISCUSSION}

The relationship between pre- and postnatal characteristics and exposures and the risk of childhood brain tumours has been investigated in many studies, often with inconclusive results. ${ }^{12}$ ${ }^{24-29}$ A birth weight $\geq 4000 \mathrm{~g}$ has been repeatedly associated with an increased risk for childhood brain tumours and other cancers. ${ }^{28,30}$ In a meta-analysis by Harder, et al. ${ }^{31}$ including 1.7 mil children and $\sim 4000$ cases, the odds ratios for the relationship between high birth weight and childhood brain tumours were 1.38 (95\%-CI: 1.07-1.79) and 1.27 (95\%-CI: 1.02-1.60), respectively for medulloblastoma and astrocytoma. We observed no such association in our study population for astrocytoma risk and birth weight from interview or registry data (Table S1 and $\mathrm{S} 2$ ). Our sample of children with a birth weight $\geq 4000 \mathrm{~g}$, however, was relatively small and the statistical power to detect an association was limited. Furthermore, since the primary aim of CEFALO was to address the risk from mobile phone use, ${ }^{21}$ our age range of 7-19 years was different to that of most other studies, usually focussed on 0-14 year olds, and the association with prenatal factors may be stronger in the youngest children as shown in Schmidt, et al. ${ }^{28}$ In 
addition, we found no indication that birth length, head circumference or maternal age at birth alters the risk of childhood brain tumours.

We found a tendency that children whose mother reported to have smoked during pregnancy had a higher risk of brain tumours compared to children of non-smoking mothers (Table 3 ). This tendency, however, was not apparent when we looked at the association using registry-recorded smoking status (Table 4). The relationship between maternal smoking and childhood brain tumour risk has been reported by a few studies ${ }^{10,32}$ but most found no evidence for an association. ${ }^{9,24,29,33,34,35}$ A meta-analysis found an overall risk estimate of 1.05 (95\%-CI: 0.90-1.21). ${ }^{36}$ Most of these studies were case-control studies that assessed the exposure retrospectively raising the question of recall bias. Recall bias could potentially be in both directions. Case mothers may over-report their smoking during pregnancy because they consider smoking a relevant risk factor to report. Or they may under-report because they do not want to be accused of having done harm to their child. A particular strength of our study is that we used prospectively collected smoking data, from the birth registry, which cannot suffer from recall bias. We found similar agreement between interview and registry data for cases and controls (Table 2), although the false positive rate was slightly higher in cases (8\%) than in controls (4\%) producing a slightly elevated odds ratio of smoking for interview compared to registry data.

The observed indication for a protective effect of maternal vitamin supplements during pregnancy is in line with other investigations, ${ }^{19,37}$ although recall bias is a concern for all these case-control studies using retrospectively collected exposure data (Table 3). This may also be of concern in our study, because we had no such data available from the birth registry. Another explanation for the observed effect is confounding. Vitamin intake during pregnancy may indicate a healthier lifestyle in general. We did not observe an association for maternal intake of vitamin supplements 
that contained folic acid. ${ }^{38}$ Non-differential exposure misclassification, however, is a plausible explanation since it can be assumed that the mothers were often not aware that the vitamin supplements they took contained folic acid. So far, the exact constituents among the multivitamins that could confer a protective effect are unknown. ${ }^{19}$

Night shift work was proposed as a risk factor for breast and endometrial cancer, ${ }^{39,40}$ and is classified as a probable carcinogen (class 2A) by the International Agency for Research on Cancer's programme on the evaluation of carcinogenic risks to humans. ${ }^{41}$ Although we did not have a large enough sample to specifically explore shift work at night, we did not see an increased risk of any brain tumours for offspring of mothers who reported any shift work (day or night) during pregnancy (Table 3). We saw a possible protective association between working, and specifically part-time work, during pregnancy and astrocytoma (Table S2) indicating a potential "healthy worker" effect. ${ }^{42}$ This result, however, was not robust. The association was found with interview data but disappeared when exposure was assigned using the birth registry data. Furthermore, no association was found in the full astrocytoma subset after adjustment for confounders (Table S1).

\section{Strengths and limitations}

In addition to the data obtained through the CEFALO questionnaire, a unique feature of our analysis is that we used birth registry data to explore the association between exposures during pregnancy and risk of childhood brain tumours, notably recorded before the diagnosis of the disease. This was possible in three of the four countries. In the Nordic Countries notification to the medical birth registers is mandatory and, for a large part of our study period, also automated. All Nordic medical birth registers are considered to be virtually complete. ${ }^{43}$ Even if birth registry data is sometimes also self-reported and subject to error and censoring (e.g. smoking status 
during pregnancy), data are collected prospectively, thus error cannot be related to health status and is expected to be non-differential. Retrospectively collected interview data, on the other hand, may result in an overestimation of the risk if cases overestimate their exposure, or in an underestimation if cases under-report exposures.

Interestingly, we noted often very slightly higher concordance for the cases than controls, which may indicate some differential exposure misclassification is at play. Since this pattern was mostly seen in the very high Kappa range $(>0.8)$, it may also simply indicate that a small proportion of control mothers are perhaps less careful or thorough in answering the questionnaire. Either way, it indicates the potential for differential exposure misclassification, which might produce biased risk estimates.

Using the international population-based CEFALO study and two independent sources of exposure data, we found no consistent associations between a variety of anthropometric factors, birth characteristics and exposures during pregnancy and risk of brain tumours among children and adolescents. Our comparison of the two sources of exposure data, however, indicates some potential for differential exposure misclassification and thus potentially biased risk estimates when relying on interview data alone. It is, therefore, reassuring that analyses of factors for which birth registry data were available were consistent with the analyses using interview data.

\section{ACKNOWLEDGEMENTS}

We would like to thank Tina Veje Andersen for coordination of fieldwork of the Danish CEFALO study and her assistance in retrieving the birth registry data, Dr Christoffer Johansen for his support of the study, and Dr Michaela Prochazka for coordinating the fieldwork of the Swedish CEFALO study. 
Financial Support: The Danish CEFALO study was supported by the Danish Strategic Research Council (grant numbers 2103-05-0006 and 2064-04-0010). The Swiss CEFALO study was supported by the Swiss Federal Office of Public Health (grant number 05.001626), the Swiss Research Foundation on Mobile Communication (grant number A2006.18), and the Swiss National Science Foundation (grant number PDFMP3_122873). The Swedish CEFALO study was supported by grants from the Swedish Council for Working Life and Social Research (grant numbers 2004-0504 and 2007-0224), the Swedish Research Council (K2008-70X-15366-04-3), the Swedish Cancer Society (09 0666), the Swedish Childhood Cancer Society (grant numbers PROJ06/050 and PROJ09/086), and the Swedish Radiation Protection Authority (SSI P 1572). The Norwegian CEFALO study was supported by the Research Council of Norway (grant number 175163/V40).

Conflicts of Interest Statement: None declared 


\section{References}

1. Gurney JG, Smith MA, Bunin GR. CNS and Miscellaneous Intracranial and Intraspinal Neoplasms ICCC III. In: Ries LAG, Smith MA, Gurney JG, Linet M, Tamra T, Young JL, Bunin GR. Cancer Incidence and Survival among Children and Adolescents: United States SEER Program 1975-1995ed. Bethedsa, MD: National Cancer Institute, SEER Program, 1999.

2. Rice JM, Wilbourn JD. Tumors of the nervous system in carcinogenic hazard identification. Toxicol Pathol 2000;28: 202-14.

3. Peris-Bonet R, Martinez-Garcia C, Lacour B, Petrovich S, Giner-Ripoll B, Navajas A, Steliarova-Foucher E. Childhood central nervous system tumours--incidence and survival in Europe (1978-1997): report from Automated Childhood Cancer Information System project. Eur J Cancer 2006;42: 2064-80.

4. Schindler M, Mitter V, Pfeiffer V, Redmond S, Wölfli P, Kuonen R, Sommer G, Spring M, Singh P, Michel G, Kuehni C, Swiss Childhood Cancer Registry Annual Report 2013/2014. Dept. of Social and Preventive Medicine, University of Bern, 2015.

5. Schmidt LS, Schmiegelow K, Lahteenmaki P, Trager C, Stokland T, Grell K, Gustafson G, Sehested A, Raashou-Nielsen O, Johansen C, Schuz J. Incidence of childhood central nervous system tumors in the Nordic countries. Pediatr Blood Cancer 2011;56: 65-9.

6. Johnson KJ, Cullen J, Barnholtz-Sloan JS, Ostrom QT, Langer CE, Turner MC, McKean-Cowdin R, Fisher JL, Lupo PJ, Partap S, Schwartzbaum JA, Scheurer ME. Childhood Brain Tumor Epidemiology: A Brain Tumor Epidemiology Consortium Review. Cancer Epidemiol Biomarkers Prev 2014;23: 2716-36.

7. Baldwin RT, Preston-Martin S. Epidemiology of brain tumors in childhood - a review. Toxicol Appl Pharmacol 2004;199: 118-31.

8. Gurney JG, Preston-Martin S, McDaniel AM, Mueller BA, Holly EA. Head injury as a risk factor for brain tumors in children: results from a multicenter case-control study. Epidemiol 1996;7: 485-9.

9. Plichart M, Menegaux F, Lacour B, Hartmann O, Frappaz D, Doz F, Bertozzi AI, Defaschelles AS, Pierre-Kahn A, Icher C, Chastagner P, Plantaz D, et al. Parental smoking, maternal alcohol, coffee and tea consumption during pregnancy and childhood malignant central nervous system tumours: the ESCALE study (SFCE). Eur J Cancer Prev 2008;17: 376-83.

10. Brooks DR, Mucci LA, Hatch EE, Cnattingius S. Maternal smoking during pregnancy and risk of brain tumors in the offspring. A prospective study of 1.4 million Swedish births. Cancer Causes Control 2004;15: 997-1005.

11. Pogoda JM, Preston-Martin S, Howe G, Lubin F, Mueller BA, Holly EA, Filippini G, Peris-Bonet R, McCredie MR, Cordier S, Choi W. An international case-control study of maternal diet during pregnancy and childhood brain tumor risk: a histology-specific analysis by food group. Ann Epidemiol 2009;19: 148-60.

12. Spector LG, Puumala SE, Carozza SE, Chow EJ, Fox EE, Horel S, Johnson KJ, McLaughlin CC, Reynolds P, Behren JV, Mueller BA. Cancer risk among children with very low birth weights. Pediatrics 2009;124: 96-104.

13. Von Behren J, Spector LG, Mueller BA, Carozza SE, Chow EJ, Fox EE, Horel S, Johnson KJ, McLaughlin C, Puumala SE, Ross JA, Reynolds P. Birth order and risk of childhood cancer: a pooled analysis from five US States. Int J Cancer 2011;128: 2709-16.

14. Shu X, Prochazka M, Lannering B, Schuz J, Röösli M, Tynes T, Kuehni CE, Andersen TV, Infanger D, Schmidt LS, Poulsen AH, Klaeboe L, et al. Atopic conditions and brain tumor 
risk in children and adolescents--an international case-control study (CEFALO). Ann Oncol 2014;25: 902-8.

15. Andersen TV, Schmidt LS, Poulsen AH, Feychting M, Röösli M, Tynes T, Aydin D, Prochazka M, Lannering B, Klaeboe L, Eggen T, Kuehni CE, et al. Patterns of exposure to infectious diseases and social contacts in early life and risk of brain tumours in children and adolescents: an International case-control study (CEFALO). Br J Cancer 2013;108: 2346-53.

16. Christensen JS, Mortensen LH, Röösli M, Feychting M, Tynes T, Andersen TV, Schmidt LS, Poulsen AH, Aydin D, Kuehni CE, Prochazka M, Lannering B, et al. Brain tumors in children and adolescents and exposure to animals and farm life: a multicenter case-control study (CEFALO). Cancer Causes Control 2012;23: 1463-73.

17. Efird JT, Holly EA, Preston-Martin S, Mueller BA, Lubin F, Filippini G, Peris-Bonet R, McCredie M, Cordier S, Arslan A, Bracci PM. Farm-related exposures and childhood brain tumours in seven countries: results from the SEARCH International Brain Tumour Study. Paediatr Perinat Epidemiol 2003;17: 201-11.

18. Feychting M, Plato N, Nise G, Ahlbom A. Paternal occupational exposures and childhood cancer. Environ Health Perspect 2001;109: 193-6.

19. Goh YI, Bollano E, Einarson TR, Koren G. Prenatal multivitamin supplementation and rates of pediatric cancers: a meta-analysis. Clin Pharmacol Ther 2007;81: 685-91.

20. Schüz J, Weihkopf T, Kaatsch P. Medication use during pregnancy and the risk of childhood cancer in the offspring. Eur J Pediatr 2007;166: 433-41.

21. Aydin D, Feychting M, Schuz J, Tynes T, Andersen TV, Schmidt LS, Poulsen AH, Johansen C, Prochazka M, Lannering B, Klaeboe L, Eggen T, et al. Mobile phone use and brain tumors in children and adolescents: a multicenter case-control study. J Natl Cancer Inst 2011;103: 1264-76.

22. Tomasetti C, Vogelstein B. Cancer etiology. Variation in cancer risk among tissues can be explained by the number of stem cell divisions. Science 2015;347: 78-81.

23. Cohen J. A coefficient of agreement for nomial scales. Educ Psychil Meas 1960;20: $37-46$.

24. Linet MS, Gridley G, Cnattingius S, Nicholson HS, Martinsson U, Glimelius B, Adami HO, Zack M. Maternal and perinatal risk factors for childhood brain tumors (Sweden). Cancer Causes Control 1996;7: 437-48.

25. Mallol-Mesnard N, Menegaux F, Lacour B, Hartmann O, Frappaz D, Doz F, Bertozzi AI, Chastagner P, Hemon D, Clavel J. Birth characteristics and childhood malignant central nervous sytem tumors: the ESCALE study (French Society for Childhood Cancer). Cancer Detect Prev 2008;32: 79-86.

26. McCredie M, Little J, Cotton S, Mueller B, Peris-Bonet R, Choi NW, Cordier S, Filippini G, Holly EA, Modan B, Arslan A, Preston-Martin S. SEARCH international case-control study of childhood brain tumours: role of index pregnancy and birth, and mother's reproductive history. Paediatr Perinat Epidemiol 1999;13: 325-41.

27. Mellemkjaer L, Hasle H, Gridley G, Johansen C, Kjaer SK, Frederiksen K, Olsen JH. Risk of cancer in children with the diagnosis immaturity at birth. Paediatr Perinat Epidemiol 2006;20: 231-7.

28. Schmidt LS, Schuz J, Lahteenmaki P, Trager C, Stokland T, Gustafson G, Hjalgrim L, Sehested A, Johansen C, Schmiegelow K. Fetal growth, preterm birth, neonatal stress and risk for CNS tumors in children: a Nordic population- and register-based case-control study. Cancer Epidemiol Biomarkers Prev 2010;19: 1042-52. 
29. Schüz J, Kaletsch U, Kaatsch P, Meinert R, Michaelis J. Risk factors for pediatric tumors of the central nervous system: results from a German population-based case-control study. Med Pediatr Oncol 2001;36: 274-82.

30. Ahlgren M, Wohlfahrt J, Olsen LW, Sorensen TI, Melbye M. Birth weight and risk of cancer. Cancer 2007;110: 412-9.

31. Harder T, Plagemann A, Harder A. Birth weight and subsequent risk of childhood primary brain tumors: a meta-analysis. Am J Epidemiol 2008;168: 366-73.

32. Filippini G, Farinotti M, Lovicu G, Maisonneuve P, Boyle P. Mothers' active and passive smoking during pregnancy and risk of brain tumours in children. Int J Cancer 1994;57: 769-74.

33. Pershagen G, Ericson A, Otterblad-Olausson P. Maternal smoking in pregnancy: does it increase the risk of childhood cancer? Int J Epidemiol 1992;21: 1-5.

34. Bunin GR, Buckley JD, Boesel CP, Rorke LB, Meadows AT. Risk factors for astrocytic glioma and primitive neuroectodermal tumor of the brain in young children: a report from the Children's Cancer Group. Cancer Epidemiol Biomarkers Prev 1994;3: 197-204.

35. Filippini G, Maisonneuve P, McCredie M, Peris-Bonet R, Modan B, Preston-Martin S, Mueller BA, Holly EA, Cordier S, Choi NW, Little J, Arslan A, et al. Relation of childhood brain tumors to exposure of parents and children to tobacco smoke: the SEARCH international casecontrol study. Surveillance of Environmental Aspects Related to Cancer in Humans. Int J Cancer 2002;100: 206-13.

36. Huncharek M, Kupelnick B, Klassen H. Maternal smoking during pregnancy and the risk of childhood brain tumors: a meta-analysis of 6566 subjects from twelve epidemiological studies. J Neurooncol 2002;57: 51-7.

37. Olshan AF, Smith JC, Bondy ML, Neglia JP, Pollock BH. Maternal vitamin use and reduced risk of neuroblastoma. Epidemiol 2002;13: 575-80.

38. Stalberg K, Haglund B, Stromberg B, Kieler H. Prenatal exposure to medicines and the risk of childhood brain tumor. Cancer Epidemiol 2010;34: 400-4.

39. Megdal SP, Kroenke CH, Laden F, Pukkala E, Schernhammer ES. Night work and breast cancer risk: a systematic review and meta-analysis. Eur J Cancer 2005;41: 2023-32.

40. Viswanathan AN, Hankinson SE, Schernhammer ES. Night shift work and the risk of endometrial cancer. Cancer Res 2007;67: 10618-22.

41. IARC. Monographs on the Evaluation of Carcinogenic Risks to Humans. Volume 98: Painting, Firefighting, and Shiftwork, 2010.

42. de Vocht F. Occupational EMF Studies. In: Röösli M. Epidemiology of Electromagnetic Fieldsed. Florida: CRC Press, 2014: 21-33.

43. Langhoff-Roos J, Krebs L, Klungsøyr K, Bjarnadottir RI, Källén K, Tapper A-M, Jakobsson M, Børdahl PE, Lindqvist PG, Gottvall K, Colmorn LB, Gissler M. The Nordic medical birth registers - a potential goldmine for clinical research. Acta Obstetricia et Gynecologica Scandinavica 2014;93: 132-7. 
Table 1. Characteristics of the study participants

\begin{tabular}{|c|c|c|c|c|}
\hline \multirow[b]{3}{*}{ Characteristic } & \multicolumn{2}{|c|}{ Full sample } & \multicolumn{2}{|c|}{ Astrocytoma subset } \\
\hline & Cases $(n=352)$ & Controls ( $n=646$ ) & Cases $(n=162)$ & Controls $(n=295)$ \\
\hline & No. (\%) & No. (\%) & No. (\%) & No. (\%) \\
\hline \multicolumn{5}{|l|}{ Country } \\
\hline Denmark & 85 (24.1) & $170(26.3)$ & $41(25.3)$ & $82(27.8)$ \\
\hline Sweden & $138(39.2)$ & $228(35.3)$ & $55(34.0)$ & $89(30.2)$ \\
\hline Norway & $44(12.5)$ & $78(12.1)$ & $23(14.2)$ & $38(12.9)$ \\
\hline Switzerland & $85(24.2)$ & $170(26.3)$ & $43(26.5)$ & $86(29.1)$ \\
\hline \multicolumn{5}{|c|}{ Age at reference date, years } \\
\hline 7-9 & $88(25.0)$ & $167(25.9)$ & 35 (21.6) & $65(22.0)$ \\
\hline $10-12$ & $82(23.3)$ & $151(23.4)$ & $46(28.4)$ & $83(28.1)$ \\
\hline $13-15$ & $99(28.1)$ & $183(28.3)$ & $43(26.5)$ & $79(26.8)$ \\
\hline $16-19$ & $83(23.6)$ & $145(22.5)$ & $38(23.5)$ & $68(23.1)$ \\
\hline \multicolumn{5}{|l|}{ Sex } \\
\hline Female & $162(46.0)$ & $293(45.4)$ & $86(53.1)$ & $161(54.6)$ \\
\hline Male & $190(54.0)$ & $353(54.6)$ & 76 (46.9) & $134(45.4)$ \\
\hline \multicolumn{5}{|c|}{ Gestational age, weeks $^{a}$} \\
\hline missing data & $118(33.5)$ & 206 (31.9) & $52(32.1)$ & $104(35.2)$ \\
\hline$<32$ & $1(0.3)$ & $4(0.6)$ & $0(0)$ & $4(1.4)$ \\
\hline $32-37$ & $9(2.6)$ & $14(2.2)$ & $4(2.5)$ & $7(2.4)$ \\
\hline$\geq 37$ & $224(63.6)$ & $422(65.3)$ & $106(65.4)$ & $180(61.0)$ \\
\hline \multicolumn{5}{|c|}{ Educational level $^{\mathrm{b}}$} \\
\hline Low & $20(5.7)$ & $26(4.0)$ & $12(7.4)$ & $10(3.4)$ \\
\hline Intermediate & $188(53.4)$ & $336(52.0)$ & $85(52.5)$ & $156(52.9)$ \\
\hline High & $144(40.9)$ & $279(43.2)$ & $65(40.1)$ & $128(43.4)$ \\
\hline Unknown & $0(0)$ & $5(0.8)$ & $0(0)$ & $1(0.3)$ \\
\hline
\end{tabular}

Notes:

a. Based on registry data, all other variables based on interview data

b. Based on highest attained level of either parent. High = graduating from university or technical college; Intermediate = elementary school, diploma school, or apprenticeship; and Low $=$ elementary school not completed 
Table 2. Agreement between interview data and birth registry data (Cohen's Kappa)

\begin{tabular}{|c|c|c|c|c|c|c|c|}
\hline Variable $^{a}$ & $\begin{array}{l}\text { Registry } \\
\text { Data }\end{array}$ & $\begin{array}{l}\text { No. } \\
\text { Overall }\end{array}$ & $\begin{array}{l}\text { Kappa } \\
\text { overall }\end{array}$ & $\begin{array}{l}\text { No. } \\
\text { Cases }\end{array}$ & $\begin{array}{l}\text { Kappa } \\
\text { cases }\end{array}$ & $\begin{array}{l}\text { No. } \\
\text { Controls }\end{array}$ & $\begin{array}{l}\text { Kappa } \\
\text { controls }\end{array}$ \\
\hline Birth weight ${ }^{b}$ & $\mathrm{SE}, \mathrm{DK}, \mathrm{NO}$ & 680 & 0.98 & 242 & 0.99 & 438 & 0.98 \\
\hline Birth length $^{c}$ & SE, DK, NO & 668 & 0.92 & 238 & 0.95 & 430 & 0.91 \\
\hline Caesarean section & SE, DK, NO & 352 & 0.95 & 135 & 1.00 & 217 & 0.91 \\
\hline Vacuum extraction & SE, DK, NO & 464 & 0.72 & 169 & 0.72 & 295 & 0.72 \\
\hline Forceps & SE, DK, NO & 454 & 0.85 & 165 & 0.89 & 289 & 0.83 \\
\hline Smoking during pregnancy ${ }^{d}$ & $\mathrm{SE}, \mathrm{NO}$ & 315 & 0.77 & 122 & 0.75 & 193 & 0.79 \\
\hline Work during pregnancy & SE & 264 & 0.54 & 97 & 0.61 & 167 & 0.50 \\
\hline Hours worked during pregnancy ${ }^{\mathrm{e}}$ & SE & 262 & 0.54 & 97 & 0.53 & 165 & 0.55 \\
\hline Ever stillbirth/miscarriage & SE, DK, NO & 252 & 0.71 & 85 & 0.71 & 167 & 0.71 \\
\hline Single or multiple births & $\mathrm{SE}, \mathrm{DK}$ & 574 & 0.96 & 203 & 1.00 & 371 & 0.94 \\
\hline
\end{tabular}

Notes:

a. Weighted kappa was used for ordinal categories: birth weight, birth length, and hours worked during pregnancy. All other variables were binary.

b. Birth weight categories based on definition of low $(<2500 \mathrm{~g})$ and high $(\geq 4000 \mathrm{~g})$ birth weight

c. Birth length categories defined based on 25 th and 75 th percentile of birth length for the control subjects

d. Binary response to interview question "did you smoke during pregnancy?" vs. Registry question "smoking at first visit to maternity clinic."

e. Hours worked during pregnancy (full time, part time, not worked) 
Table 3. Relationship between exposures and brain tumour risk among children and adolescents based on interview data

\begin{tabular}{|c|c|c|c|c|}
\hline Variable & $\begin{array}{c}\text { Cases } \\
\text { No. }\end{array}$ & $\begin{array}{c}\text { Controls } \\
\text { No. }\end{array}$ & $\begin{array}{l}\text { OR (95\%-CI) } \\
\text { Unadjusted }\end{array}$ & $\begin{array}{l}\text { OR }(95 \%-C l)^{a} \\
\text { Adjusted }^{\mathrm{b}}\end{array}$ \\
\hline \multicolumn{5}{|c|}{ Anthropometric factors: } \\
\hline \multicolumn{5}{|c|}{ Birth weight ${ }^{c}$} \\
\hline$<2500 \mathrm{~g}$ & 20 & 25 & $1.45(0.79-2.66)$ & $1.53(0.83-2.82)$ \\
\hline $2500-4000 \mathrm{~g}$ & 274 & 508 & 1.0 & 1.0 \\
\hline$\geq 4000 \mathrm{~g}$ & 53 & 95 & $1.06(0.73-1.54)$ & $1.09(0.74-1.58)$ \\
\hline$p$ value for trend & & & & 0.581 \\
\hline \multicolumn{5}{|l|}{ Birth length $^{d}$} \\
\hline$\leq 49 \mathrm{~cm}$ & 104 & 180 & $1.05(0.76-1.44)$ & $1.03(0.75-1.42)$ \\
\hline $50-52 \mathrm{~cm}$ & 163 & 295 & 1.0 & 1.0 \\
\hline$\geq 53 \mathrm{~cm}$ & 67 & 122 & $1.04(0.72-1.49)$ & $1.04(0.72-1.49)$ \\
\hline$p$ value for trend & & & & 0.744 \\
\hline \multicolumn{5}{|l|}{ Age of the mother } \\
\hline$<25$ years & 80 & 120 & 1.0 & 1.0 \\
\hline $25-29$ & 131 & 249 & $0.81(0.56-1.16)$ & $0.82(0.57-1.19)$ \\
\hline $30-34$ & 97 & 181 & $0.82(0.56-1.22)$ & $0.85(0.57-1.26)$ \\
\hline$\geq 35$ & 41 & 85 & $0.73(0.46-1.16)$ & $0.74(0.46-1.18)$ \\
\hline$p$ value for trend & & & & 0.158 \\
\hline \multicolumn{5}{|l|}{ Birth characteristics: } \\
\hline \multicolumn{5}{|l|}{ Caesarean section } \\
\hline No & 300 & 541 & 1.0 & 1.0 \\
\hline Yes & 47 & 86 & $0.98(0.66-1.45)$ & $0.99(0.67-1.48)$ \\
\hline \multicolumn{5}{|c|}{ Vacuum extraction } \\
\hline No & 304 & 541 & 1.0 & 1.0 \\
\hline Yes & 40 & 74 & $0.99(0.64-1.52)$ & $0.98(0.63-1.51)$ \\
\hline \multicolumn{5}{|l|}{ Forceps } \\
\hline No & 334 & 599 & 1.0 & 1.0 \\
\hline Yes & 10 & 16 & $1.13(0.49-2.64)$ & $1.11(0.47-2.61)$ \\
\hline \multicolumn{5}{|c|}{ Born premature (at least 3 weeks too early) } \\
\hline No & 318 & 558 & 1.0 & 1.0 \\
\hline Yes & 26 & 52 & $0.86(0.53-1.40)$ & $0.85(0.52-1.39)$ \\
\hline \multicolumn{5}{|c|}{ Ever stillbirth/miscarriage } \\
\hline No & 239 & 413 & 1.0 & 1.0 \\
\hline Yes & 104 & 196 & $0.92(0.69-1.22)$ & $0.92(0.69-1.23)$ \\
\hline \multicolumn{5}{|l|}{ Birth order } \\
\hline 1st born & 148 & 254 & 1.0 & 1.0 \\
\hline$\geq 2$ nd born & 203 & 385 & $0.87(0.67-1.14)$ & $0.90(0.68-1.20)$ \\
\hline \multicolumn{5}{|c|}{ Single or multiple births } \\
\hline Singleton & 342 & 622 & 1.0 & 1.0 \\
\hline Multiple birth & 8 & 15 & $1.00(0.41-2.41)$ & $1.04(0.43-2.53)$ \\
\hline
\end{tabular}




\begin{tabular}{|c|c|c|c|c|}
\hline Variable & $\begin{array}{c}\text { Cases } \\
\text { No. }\end{array}$ & $\begin{array}{c}\text { Controls } \\
\text { No. }\end{array}$ & $\begin{array}{l}\text { OR }(95 \%-C l)^{a} \\
\text { Unadjusted }\end{array}$ & $\begin{array}{c}\text { OR }(95 \%-C l)^{a} \\
\text { Adjusted }^{b}\end{array}$ \\
\hline \multicolumn{5}{|l|}{ Exposures: } \\
\hline \multicolumn{5}{|c|}{ Maternal smoking during pregnancy } \\
\hline No & 258 & 493 & 1.0 & 1.0 \\
\hline Yes & 90 & 133 & $1.27(0.94-1.73)$ & $1.23(0.90-1.68)$ \\
\hline \multicolumn{5}{|c|}{ Maternal vitamin intake during pregnancy } \\
\hline No & 189 & 290 & 1.0 & 1.0 \\
\hline Yes & 139 & 289 & $0.75(0.56-1.01)$ & $0.75(0.56-1.01)$ \\
\hline \multicolumn{5}{|c|}{ Maternal vitamin and folic acid intake during pregnancy } \\
\hline No & 230 & 380 & 1.0 & 1.0 \\
\hline Yes & 59 & 93 & $1.10(0.75-1.61)$ & $1.15(0.78-1.70)$ \\
\hline \multicolumn{5}{|l|}{ Work during pregnancy } \\
\hline No & 99 & 154 & 1.0 & 1.0 \\
\hline Yes & 248 & 471 & $0.80(0.59-1.08)$ & $0.82(0.61-1.12)$ \\
\hline \multicolumn{5}{|l|}{ Hours worked during pregnancy } \\
\hline Not worked & 99 & 154 & 1.0 & 1.0 \\
\hline Part-time ( $<40$ hours/week) & 165 & 313 & $0.80(0.58-1.11)$ & $0.84(0.60-1.17)$ \\
\hline Full time (40 hours/week) & 81 & 149 & $0.81(0.55-1.19)$ & $0.83(0.57-1.23)$ \\
\hline$p$ value for trend & & & & 0.255 \\
\hline \multicolumn{5}{|l|}{ Shift work during pregnancy } \\
\hline Not worked or not shift worked & 287 & 520 & 1.0 & 1.0 \\
\hline Shift worked & 59 & 102 & $1.00(0.69-1.45)$ & $0.99(0.68-1.44)$ \\
\hline \multicolumn{5}{|l|}{ Maternal diabetes $^{\mathrm{e}}$} \\
\hline No & 341 & 610 & 1.0 & 1.0 \\
\hline Yes & 6 & 14 & $0.76(0.29-2.00)$ & $0.76(0.29-2.02)$ \\
\hline
\end{tabular}

Notes:

a. Conditional logistic regression models, matched on sex, age-group and geographical region

b. Adjusted for maternal age and parental education

c. Birth weight categories based on definition of low $(<2500 \mathrm{~g})$ and high $(\geq 4000 \mathrm{~g})$ birth weight

d. Birth length categories defined based on 25th and 75th percentile of birth length for the control subjects

e. Defined as existing maternal diabetes or maternal gestational diabetes 
Table 4. Comparison of brain tumour risk among children and adolescents based on interview vs. birth registry data, based on the study population where both types of data are available

\begin{tabular}{|c|c|c|c|c|c|c|c|}
\hline \multirow{3}{*}{ Variable } & \multicolumn{2}{|c|}{ Interview data } & \multicolumn{4}{|c|}{ Birth Registry data } & \multirow{3}{*}{$\begin{array}{l}\text { Registry } \\
\text { Data }\end{array}$} \\
\hline & Cases & Controls & OR $(95 \%-\mathrm{Cl})^{a}$ & Cases & Controls & OR $(95 \%-\mathrm{Cl})^{a}$ & \\
\hline & No. & No. & Adjusted $^{b}$ & No. & No. & Adjusted $^{b}$ & \\
\hline \multicolumn{8}{|l|}{ Anthropometric factors: } \\
\hline Birth weight ${ }^{c}$ & & & & & & & SE, DK, NO \\
\hline$<2500 \mathrm{~g}$ & 12 & 13 & $1.66(0.72-3.86)$ & 11 & 14 & $1.42(0.63-3.21)$ & \\
\hline $2500-4000 \mathrm{~g}$ & 177 & 313 & 1.0 & 178 & 313 & 1.0 & \\
\hline$\geq 4000 \mathrm{~g}$ & 47 & 71 & $1.31(0.85-2.01)$ & 47 & 70 & $1.33(0.86-2.05)$ & \\
\hline$p$ value for trend & & & 0.743 & & & 0.488 & \\
\hline Birth length $^{d}$ & & & & & & & SE, DK, NO \\
\hline$\leq 49 \mathrm{~cm}$ & 58 & 93 & $0.96(0.62-1.48)$ & 59 & 94 & $0.96(0.62-1.48)$ & \\
\hline $50-52 \mathrm{~cm}$ & 120 & 194 & 1.0 & 121 & 193 & 1.0 & \\
\hline$\geq 53 \mathrm{~cm}$ & 54 & 97 & $0.98(0.64-1.50)$ & 52 & 97 & $0.91(0.59-1.41)$ & \\
\hline$p$ value for trend & & & 0.641 & & & 0.565 & \\
\hline Head circumference ${ }^{e}$ & & & & & & & SE, DK, NO \\
\hline$<38 \mathrm{~cm}$ & - & - & - & 157 & 246 & 1.0 & \\
\hline$\geq 38 \mathrm{~cm}$ & - & - & - & 6 & 10 & $1.08(0.37-3.15)$ & \\
\hline Gestational age (per week) & - & - & - & 227 & 383 & $1.00(0.91-1.08)$ & SE, DK, NO \\
\hline \multicolumn{8}{|l|}{ Birth characteristics: } \\
\hline Caesarean section & & & & & & & SE, DK, NO \\
\hline No & 103 & 159 & 1.0 & 103 & 161 & 1.0 & \\
\hline Yes & 19 & 26 & $0.88(0.44-1.78)$ & 19 & 24 & $0.96(0.47-1.97)$ & \\
\hline Vacuum extraction & & & & & & & SE, DK, NO \\
\hline No & 141 & 235 & 1.0 & 150 & 241 & 1.0 & \\
\hline Yes & 17 & 23 & $1.09(0.53-2.23)$ & 8 & 17 & $0.66(0.25-1.74)$ & \\
\hline No & 154 & 252 & 1.0 & 155 & 254 & 1.0 & \\
\hline Yes & 3 & 5 & $0.93(0.21-4.10)$ & 2 & 3 & $1.28(0.20-8.10)$ & \\
\hline Ever stillbirth/miscarriage & & & & & & & SE, DK, NO \\
\hline No & 45 & 83 & 1.0 & 55 & 102 & 1.0 & \\
\hline Yes & 24 & 44 & $0.91(0.46-1.80)$ & 14 & 25 & $0.94(0.38-2.33)$ & \\
\hline \multicolumn{8}{|l|}{ Single or multiple births } \\
\hline Singleton & 194 & 327 & 1.0 & 194 & 328 & 1.0 & SE, DK \\
\hline Multiple birth & 4 & 9 & $0.84(0.24-2.94)$ & 4 & 8 & $0.92(0.26-3.34)$ & \\
\hline Parity $^{e, f}$ & & & & & & & DK, NO \\
\hline first birth & - & - & - & 20 & 28 & 1.0 & \\
\hline not first birth & - & - & - & 33 & 67 & $0.75(0.33-1.71)$ & \\
\hline \multicolumn{8}{|l|}{ Exposures: } \\
\hline \multicolumn{3}{|c|}{ Maternal smoking during pregnancy } & & & & & SE, NO \\
\hline No & 85 & 129 & 1.0 & 90 & 127 & 1.0 & \\
\hline Yes & 29 & 37 & $1.25(0.68-2.26)$ & 24 & 39 & $0.96(0.53-1.75)$ & \\
\hline
\end{tabular}




\begin{tabular}{|c|c|c|c|c|c|c|c|}
\hline \multirow{3}{*}{ Variable } & \multicolumn{3}{|c|}{ Interview data } & \multicolumn{4}{|c|}{ Birth Registry data } \\
\hline & \multirow{2}{*}{$\begin{array}{c}\text { Cases } \\
\text { No. }\end{array}$} & \multirow{2}{*}{$\begin{array}{c}\text { Controls } \\
\text { No. }\end{array}$} & \multirow{2}{*}{$\begin{array}{l}\text { OR }(95 \%-\mathrm{Cl})^{a} \\
\text { Adjusted }^{b}\end{array}$} & \multirow{2}{*}{$\begin{array}{c}\text { Cases } \\
\text { No. }\end{array}$} & \multirow{2}{*}{$\begin{array}{c}\text { Controls } \\
\text { No. }\end{array}$} & \multirow{2}{*}{$\begin{array}{l}\text { OR }(95 \%-\mathrm{Cl})^{\mathrm{a}} \\
\text { Adjusted }^{\mathrm{b}}\end{array}$} & \multirow{2}{*}{$\begin{array}{l}\text { Registry } \\
\text { Data }\end{array}$} \\
\hline & & & & & & & \\
\hline Work during pregnancy & & & & & & & SE \\
\hline No & 14 & 19 & 1.0 & 11 & 14 & 1.0 & \\
\hline Yes & 69 & 92 & $0.76(0.31-1.86)$ & 72 & 97 & $0.77(0.30-1.95)$ & \\
\hline Hours worked during pregna & & & & & & & SE \\
\hline Not worked & 14 & 19 & 1.0 & 11 & 14 & 1.0 & \\
\hline Part-time (<40 hours/week) & 38 & 41 & $0.92(0.35-2.42)$ & 30 & 40 & $0.77(0.29-2.06)$ & \\
\hline Full time (40 hours/week) & 31 & 50 & $0.68(0.27-1.73)$ & 42 & 56 & $0.78(0.29-2.08)$ & \\
\hline$p$ value for trend & & & 0.160 & & & 0.292 & \\
\hline
\end{tabular}

Notes:

a. Conditional logistic regression models, matched on sex, age-group and geographical region

b. Adjusted for maternal age and parental education

c. Birth weight categories based on definition of low $(<2500 \mathrm{~g})$ and high birth weight $(>=4000 \mathrm{~g})$

d. Birth length categories defined based on 25th and 75th percentile of birth length for the control subjects

e. Head circumference, gestational age and parity were not inquired in the interview

f. Parity adjusted for maternal age only 


\section{Supplemental Information:}

\section{A multinational case-control study on childhood brain tumours, anthropogenic} factors, birth characteristics and prenatal exposures: a validation of interview data

Danielle Vienneau, ${ }^{1,2 \#}$ Denis Infanger, ${ }^{1,2 \#}$ Maria Feychting, ${ }^{3}$ Joachim Schüz,${ }^{4,5}$ Lisbeth Samsø Schmidt, ${ }^{4,6}$ Aslak Harbo Poulsen, ${ }^{4}$ Giorgio Tettamanti, ${ }^{3}$ Lars Klæboe, ${ }^{7,8}$ Claudia E. Kuehni, ${ }^{9}$ Tore Tynes, ${ }^{7,10}$ Nicolas Von der Weid ${ }^{11}$, Birgitta Lannering ${ }^{12}$ and Martin Röösli ${ }^{1,2 *}$

${ }^{1}$ Department of Epidemiology and Public Health, Swiss Tropical and Public Health Institute, Basel, Switzerland, ${ }^{2}$ University of Basel, Switzerland, ${ }^{3}$ Institute of Environmental Medicine, Unit of Epidemiology, Karolinska Institutet, Stockholm, Sweden, ${ }^{4}$ Danish Cancer Society Research Center, Danish Cancer Society, Copenhagen, Denmark, ${ }^{5}$ International Agency for Research on Cancer (IARC), Section of Environment and Radiation, Lyon, France, ${ }^{6}$ University Hospital Rigshospitalet Copenhagen Denmark, ${ }^{7}$ The Cancer Registry of Norway, Oslo, Norway, ${ }^{8}$ Norwegian Radiation Protection Authority, Østerås, Norway, ${ }^{9}$ Institute of Social and Preventive Medicine, University of Berne, Switzerland, ${ }^{10}$ National Institute of Occupational Health, Oslo, Norway, ${ }^{11}$ Pediatric Hematology-Oncology, University of Basel Children's Hospital, Basel, Switzerland, ${ }^{12}$ Department of Pediatrics, University of Gothenburg, The Queen Silvia Children's Hospital, Göteborg, Sweden, ${ }^{\#}$ Joint first authorship 
Table S1. Relationship between exposures and astrocytoma risk among children and adolescents based on interview data

\begin{tabular}{|c|c|c|c|c|}
\hline Variable & $\begin{array}{c}\text { Cases } \\
\text { No. }\end{array}$ & $\begin{array}{c}\text { Controls } \\
\text { No. }\end{array}$ & $\begin{array}{c}\text { OR }(95 \%-\mathrm{Cl})^{\mathrm{a}} \\
\text { Unadjusted }\end{array}$ & $\begin{array}{c}\text { OR }(95 \%-C l)^{a} \\
\text { Adjusted }^{b}\end{array}$ \\
\hline \multicolumn{5}{|c|}{ Anthropometric factors: } \\
\hline \multicolumn{5}{|c|}{ Birth weight ${ }^{c}$} \\
\hline$<2500 \mathrm{~g}$ & 9 & 18 & $0.81(0.35-1.90)$ & $0.84(0.35-1.99)$ \\
\hline $2500-4000 \mathrm{~g}$ & 129 & 222 & 1.0 & 1.0 \\
\hline$\geq 4000 \mathrm{~g}$ & 22 & 46 & $0.84(0.48-1.47)$ & $0.90(0.51-1.59)$ \\
\hline$p$ value for trend & & & & 0.711 \\
\hline \multicolumn{5}{|l|}{ Birth length $^{d}$} \\
\hline$\leq 49 \mathrm{~cm}$ & 54 & 84 & $1.16(0.74-1.80)$ & $1.10(0.70-1.74)$ \\
\hline $50-52 \mathrm{~cm}$ & 71 & 135 & 1.0 & 1.0 \\
\hline$\geq 53 \mathrm{~cm}$ & 30 & 53 & $1.06(0.62-1.80)$ & $1.05(0.61-1.80)$ \\
\hline$p$ value for trend & & & & 0.640 \\
\hline \multicolumn{5}{|l|}{ Age of the mother } \\
\hline$<25$ years & 33 & 47 & 1.0 & 1.0 \\
\hline $25-29$ & 62 & 120 & $0.75(0.42-1.31)$ & $0.85(0.47-1.51)$ \\
\hline $30-34$ & 45 & 83 & $0.83(0.45-1.51)$ & $0.93(0.50-1.72)$ \\
\hline$\geq 35$ & 20 & 39 & $0.72(0.36-1.45)$ & $0.77(0.38-1.57)$ \\
\hline$p$ value for trend & & & & 0.380 \\
\hline \multicolumn{5}{|l|}{ Birth characteristics: } \\
\hline \multicolumn{5}{|l|}{ Caesarean section } \\
\hline No & 132 & 245 & 1.0 & 1.0 \\
\hline Yes & 28 & 40 & $1.26(0.73-2.15)$ & $1.28(0.74-2.23)$ \\
\hline \multicolumn{5}{|c|}{ Vacuum extraction } \\
\hline No & 138 & 243 & 1.0 & 1.0 \\
\hline Yes & 19 & 33 & $1.05(0.56-1.97)$ & $1.08(0.57-2.03)$ \\
\hline \multicolumn{5}{|l|}{ Forceps } \\
\hline No & 150 & 267 & 1.0 & 1.0 \\
\hline Yes & 7 & 9 & $1.54(0.51-4.62)$ & $1.43(0.47-4.39)$ \\
\hline \multicolumn{5}{|c|}{ Born premature (at least 3 weeks too early) } \\
\hline No & 147 & 251 & 1.0 & 1.0 \\
\hline Yes & 12 & 26 & $0.77(0.38-1.54)$ & $0.78(0.38-1.58)$ \\
\hline \multicolumn{5}{|c|}{ Ever stillbirth/miscarriage } \\
\hline No & 110 & 193 & 1.0 & 1.0 \\
\hline Yes & 48 & 83 & $1.02(0.67-1.57)$ & $1.01(0.65-1.56)$ \\
\hline \multicolumn{5}{|l|}{ Birth order } \\
\hline 1st born & 71 & 125 & 1.0 & 1.0 \\
\hline$\geq 2$ nd born & 91 & 167 & $0.96(0.65-1.41)$ & $0.97(0.64-1.47)$ \\
\hline \multicolumn{5}{|c|}{ Single or multiple births } \\
\hline Singleton & 158 & 282 & 1.0 & 1.0 \\
\hline Multiple birth & 4 & 10 & $0.74(0.22-2.47)$ & $0.84(0.25-2.88)$ \\
\hline
\end{tabular}




\begin{tabular}{|c|c|c|c|c|}
\hline Variable & $\begin{array}{c}\text { Cases } \\
\text { No. }\end{array}$ & $\begin{array}{c}\text { Controls } \\
\text { No. }\end{array}$ & $\begin{array}{l}\text { OR }(95 \%-\mathrm{Cl})^{\mathrm{a}} \\
\text { Unadjusted }\end{array}$ & $\begin{array}{c}\text { OR }(95 \%-C l)^{a} \\
\text { Adjusted }^{b}\end{array}$ \\
\hline \multicolumn{5}{|l|}{ Exposures: } \\
\hline \multicolumn{5}{|c|}{ Maternal smoking during pregnancy } \\
\hline No & 120 & 227 & 1.0 & 1.0 \\
\hline Yes & 41 & 58 & $1.34(0.84-2.13)$ & $1.26(0.78-2.04)$ \\
\hline \multicolumn{5}{|c|}{ Maternal vitamin intake during pregnancy } \\
\hline No & 83 & 132 & 1.0 & 1.0 \\
\hline Yes & 65 & 129 & $0.81(0.52-1.27)$ & $0.76(0.48-1.20)$ \\
\hline \multicolumn{5}{|c|}{ Maternal vitamin and folic acid intake during pregnancy } \\
\hline No & 105 & 178 & 1.0 & 1.0 \\
\hline Yes & 29 & 38 & $1.34(0.75-2.40)$ & $1.41(0.77-2.58)$ \\
\hline \multicolumn{5}{|l|}{ Work during pregnancy } \\
\hline No & 56 & 78 & 1.0 & 1.0 \\
\hline Yes & 104 & 206 & $0.65(0.42-1.01)$ & $0.70(0.45-1.09)$ \\
\hline \multicolumn{5}{|l|}{ Hours worked during pregnancy } \\
\hline Not worked & 56 & 78 & 1.0 & 1.0 \\
\hline Part-time (<40 hours/week) & 74 & 143 & $0.67(0.41-1.08)$ & $0.75(0.46-1.24)$ \\
\hline Full time (40 hours/week) & 29 & 59 & $0.66(0.38-1.17)$ & $0.70(0.39-1.24)$ \\
\hline$p$ value for trend & & & & 0.130 \\
\hline \multicolumn{5}{|l|}{ Shift work during pregnancy } \\
\hline Not worked or not shift worked & 146 & 242 & 1.0 & 1.0 \\
\hline Shift worked & 14 & 42 & $0.50(0.26-0.95)$ & $0.52(0.27-1.01)$ \\
\hline \multicolumn{5}{|l|}{ Maternal diabetes ${ }^{e}$} \\
\hline No & 155 & 279 & 1.0 & 1.0 \\
\hline Yes & 5 & 4 & $2.33(0.62-8.72)$ & $2.80(0.72-10.93)$ \\
\hline
\end{tabular}

Notes:

a. Conditional logistic regression models, matched on sex, age-group and geographical region

b. Adjusted for maternal age and parental education

c. Birth weight categories based on definition of low $(<2500 \mathrm{~g})$ and high $(\geq 4000 \mathrm{~g})$ birth weight

d. Birth length categories defined based on 25 th and 75 th percentile of birth length for the control subjects

e. Defined as existing maternal diabetes or maternal gestational diabetes 
Table S2. Comparison of astrocytoma risk among children and adolescents based on interview vs. birth registry data based on the study population, where both types of data are available

\begin{tabular}{|c|c|c|c|c|c|c|c|}
\hline \multirow{3}{*}{ Variable } & \multicolumn{3}{|c|}{ Interview data } & \multicolumn{4}{|c|}{ Birth Registry data } \\
\hline & Cases & Controls & OR $(95 \%-\mathrm{Cl})^{a}$ & Cases & Controls & OR $(95 \%-C I)^{a}$ & Registry \\
\hline & No. & No. & Adjusted $^{\mathrm{b}}$ & No. & No. & Adjusted $^{\mathrm{b}}$ & \\
\hline \multicolumn{8}{|l|}{ Anthropometric factors: } \\
\hline Birth weight ${ }^{c}$ & & & & & & & SE, DK, NO \\
\hline$<2500 \mathrm{~g}$ & 5 & 10 & $0.70(0.21-2.37)$ & 4 & 11 & $0.57(0.17-1.86)$ & \\
\hline $2500-4000 \mathrm{~g}$ & 83 & 137 & 1.0 & 84 & 137 & 1.0 & \\
\hline$\geq 4000 \mathrm{~g}$ & 19 & 32 & $1.18(0.60-2.34)$ & 19 & 31 & $1.20(0.60-2.42)$ & \\
\hline$p$ value for trend & & & 0.894 & & & 0.629 & \\
\hline Birth length $^{d}$ & & & & & & & SE, DK, NO \\
\hline$\leq 49 \mathrm{~cm}$ & 29 & 45 & $0.84(0.43-1.64)$ & 31 & 45 & $0.99(0.51-1.93)$ & \\
\hline $50-52 \mathrm{~cm}$ & 51 & 82 & 1.0 & 49 & 83 & 1.0 & \\
\hline$\geq 53 \mathrm{~cm}$ & 24 & 41 & $0.98(0.52-1.86)$ & 24 & 40 & $1.07(0.56-2.06)$ & \\
\hline$p$ value for trend & & & 0.544 & & & 0.477 & \\
\hline Head circumference ${ }^{e}$ & & & & & & & $\mathrm{SE}, \mathrm{DK}, \mathrm{NO}$ \\
\hline$<38 \mathrm{~cm}$ & - & - & - & 71 & 109 & 1.0 & \\
\hline$\geq 38 \mathrm{~cm}$ & - & - & - & 3 & 6 & $1.03(0.24-4.42)$ & \\
\hline Gestational age (per week) & - & - & - & 106 & 179 & $1.02(0.91-1.15)$ & SE, DK, NO \\
\hline \multicolumn{8}{|l|}{ Birth characteristics: } \\
\hline Caesarean section & 40 & 65 & 1.0 & 40 & 65 & 1.0 & SE, DK, NO \\
\hline No & 12 & 13 & $1.24(0.40-3.82)$ & 12 & 13 & $1.24(0.40-3.82)$ & \\
\hline \multicolumn{8}{|l|}{ Yes } \\
\hline Vacuum extraction & 57 & 98 & 1.0 & 61 & 100 & 1.0 & SE, DK, NO \\
\hline No & 8 & 9 & $1.13(0.34-3.75)$ & 4 & 7 & $0.84(0.19-3.68)$ & \\
\hline \multicolumn{8}{|l|}{ Yes } \\
\hline No & 64 & 104 & 1.0 & 64 & 105 & 1.0 & \\
\hline Yes & 1 & 3 & $0.53(0.05-5.36)$ & 1 & 2 & $0.98(0.08-11.55)$ & \\
\hline Ever stillbirth/miscarriage & & & & & & & SE, DK, NO \\
\hline No & 24 & 41 & 1.0 & 26 & 48 & 1.0 & \\
\hline Yes & 8 & 18 & $0.71(0.23-2.19)$ & 6 & 11 & $0.83(0.22-3.13)$ & \\
\hline \multicolumn{8}{|l|}{ Single or multiple births } \\
\hline Singleton & 85 & 146 & 1.0 & 85 & 146 & 1.0 & SE, DK \\
\hline Multiple birth & 3 & 5 & $1.03(0.21-5.13)$ & 3 & 5 & $1.03(0.21-5.13)$ & \\
\hline Parity $^{e, f}$ & & & & & & & DK, NO \\
\hline first birth & - & - & - & 12 & 16 & 1.0 & \\
\hline not first birth & - & - & - & 17 & 33 & $0.73(0.22-2.41)$ & \\
\hline \multicolumn{8}{|l|}{ Exposures: } \\
\hline \multicolumn{3}{|c|}{ Maternal smoking during pregnancy } & & & & & $\mathrm{SE}, \mathrm{NO}$ \\
\hline No & 34 & 51 & 1.0 & 37 & 49 & 1.0 & \\
\hline Yes & 13 & 17 & $0.97(0.35-2.68)$ & 10 & 19 & $0.59(0.22-1.58)$ & \\
\hline Work during pregnancy & & & & & & & SE \\
\hline No & 9 & 5 & 1.0 & 7 & 1 & 1.0 & \\
\hline Yes & 22 & 35 & $0.14(0.02-0.97)$ & 24 & 39 & $0.14(0.01-1.29)$ & \\
\hline
\end{tabular}


Interview data

\begin{tabular}{|c|c|c|c|c|c|c|c|}
\hline \multirow{3}{*}{ Variable } & \multicolumn{3}{|c|}{ Interview data } & \multicolumn{3}{|c|}{ BIrth Registry data } & \multirow{3}{*}{$\begin{array}{l}\text { Registry } \\
\text { Data }\end{array}$} \\
\hline & Cases & Controls & OR $(95 \%-\mathrm{Cl})^{a}$ & Cases & Controls & OR $(95 \%-\mathrm{Cl})^{a}$ & \\
\hline & No. & No. & Adjusted $^{\mathrm{b}}$ & No. & No. & Adjusted $^{\mathrm{b}}$ & \\
\hline \multicolumn{3}{|c|}{ Hours worked during pregnancy } & & & & & SE \\
\hline Not worked & 9 & 5 & 1.0 & 7 & 1 & 1.0 & \\
\hline Part-time (<40 hours/week) & 11 & 18 & $0.09(0.01-0.97)$ & 9 & 17 & $0.13(0.01-1.29)$ & \\
\hline Full time (40 hours/week) & 11 & 17 & $0.15(0.02-1.06)$ & 15 & 22 & $0.15(0.01-1.43)$ & \\
\hline$p$ value for trend & & & 0.073 & & & 0.035 & \\
\hline
\end{tabular}

Notes:

a. Conditional logistic regression models, matched on sex, age-group and geographical region

b. Adjusted for maternal age and parental education

c. Birth weight categories based on definition of low $(<2500 \mathrm{~g})$ and high birth weight $(>=4000 \mathrm{~g})$

d. Birth length categories defined based on 25th and 75th percentile of birth length for the control subjects

e. Head circumference and parity were not inquired in the interview

f. Parity adjusted for maternal age only 